\title{
Characterization of human iPS cell-derived cardiomyocyte sheets as a model to detect drug-induced conduction disturbance
}

\author{
Hiroko Izumi-Nakaseko', Yuji Nakamura1, Takeshi Wada', Kentaro Ando", \\ Yasunari Kanda'2, Yuko Sekino² and Atsushi Sugiyama ${ }^{1}$ \\ ${ }^{1}$ Department of Pharmacology, Faculty of Medicine, Toho University, 5-21-16 Omori-nishi, Ota-ku, Tokyo 143-8540, Japan \\ ${ }^{2}$ Division of Pharmacology, National Institute of Health Sciences, 1-18-1 Kamiyoga, Setagaya-ku, Tokyo 158-8501, Japan
}

(Received December 14, 2016; Accepted January 26, 2017)

\begin{abstract}
In order to characterize human induced pluripotent stem cell-derived cardiomyocytes (hiPSC-CMs) sheets as a model for detecting drug-induced conduction disturbance, we examined their electrophysiological and electropharmacological properties by using the multi-electrode array system with a programmed electrical stimulation protocol. At pre-drug control, the conduction speed, effective refractory period and field potential duration were $0.14 \pm 0.01 \mathrm{~m} / \mathrm{sec}, 453 \pm 10 \mathrm{msec}$ and $361 \pm 9 \mathrm{msec}$, respectively at a cycle length of $1,000 \mathrm{msec}(\mathrm{n}=18)$. Shortening the pacing cycle length from 1,000 to 600 msec decreased the conduction speed and field potential duration, but prolonged the effective refractory period. Disopyramide, lidocaine and flecainide decreased the conduction speed but prolonged the effective refractory period and field potential duration, whereas the reverse was true for verapamil. Thus, conduction properties of the cell sheet may largely depend on the extent of $\mathrm{Na}^{+}$channel availability as is the case in the human ventricle. Importantly, there was no relationship between the conduction delay and $1^{\text {st }}$ spike amplitude reduction after the treatment of $\mathrm{Na}^{+}$channel blockers. These findings may provide crucial guide on future application of this new technology for early phase safety pharmacological screening of new chemical entities.
\end{abstract}

Key words: iPS, Cardiomyocytes, Conduction, Effective refractory period, Field potential duration

\section{INTRODUCTION}

Human induced pluripotent stem cell-derived cardiomyocytes (hiPSC-CMs) are known to express multiple cardiac ion channels, profiles of which can be similar to those in human intact heart (Ma et al., 2011; Navarrete et al., 2013). In order to evaluate the utility of hiPSC-CMs as a tool for detecting drug-induced electrophysiological modifications, the effects of various drugs and chemical compounds have been assessed on the action potential waveform of single hiPSC-CM (Gibson et al., 2014; Peng et al., 2010) as well as the field potential configuration of two-dimensional cell sheets of hiPSC-CMs (Harris et al., 2013; Mehta et al., 2013; Nakamura et al., 2014; Nozaki et al., 2014; Uesugi et al., 2014). Thus, hiPSC-CMs have been well recognized as a new strategy that can provide reliable information for predicting drug-induced repolari- zation delay in the human heart.

Drug-induced intraventricular conduction delay has been known to cause dys-synchrony of the ventricular contraction, enhancing pump failure, whereas it may develop a substrate for re-entrant excitation circuit, resulting in the onset of ventricular tachyarrhythmias (Miller and Zipes, 2008). At present, the drug-induced intraventricular conduction delay has been largely assessed with the isolated papillary muscle, Langendorff perfused in vitro heart and electrocardiogram in the in vivo animals, of which throughput is not necessarily so high as that needed for early screening of drug candidates. Although hiPSC-CMs sheet has been expected to become an alternative for such classical methods, electropharmacological information particularly on its conduction properties is still limited (Kadota et al., 2013; Lee et al., 2012; Mehta et al., 2013).

Correspondence: Atsushi Sugiyama (E-mail: atsushi.sugiyama@med.toho-u.ac.jp) 


\section{H. Izumi-Nakaseko et al.}

Here, we examined the conduction property, field potential duration and effective refractory period of the hiPSC-CMs sheet by using the multi-electrode array system with programmed electrical stimulation protocol in the presence and absence of $\mathrm{Na}^{+}$and $\mathrm{Ca}^{2+}$ channel blockers (Task Force of the Working Group on Arrhythmias of the European Society of Cardiology, 1991; Vaughan Williams, 1992). In addition, we assessed the effect of the drugs on $1^{\text {st }}$ spike amplitude of the field potential to analyze whether it can be used for estimating the druginduced conduction changes. This is the first report that precisely characterized the electrophysiological and eletropharmacological profile of the hiPSC-CMs sheet within the range of the human heart rate.

\section{MATERIALS AND METHODS}

\section{Culture of hiPSC-CMs}

Cryopreserved hiPSC-CMs (iCell Cardiomyocytes; Cellular Dynamics International (CDI), Madison, WI, USA) were cultured as previously described (Nakamura et al., 2014; Uesugi et al., 2014). The 64-microelectrode array (MED probe; MED-P515A, Alpha MED Scientific, Inc., Osaka, Japan) was placed into a 25-mmdiameter chamber. An area of $1 \mathrm{~mm}^{2}$ of the surface of the array was coated with $2 \mu \mathrm{L}$ of fibronectin $(50 \mu \mathrm{g}$ in $1 \mathrm{~mL}$ of D-PBS(-) $(1 \times$, nacalai tesque, Inc., Kyoto, Japan) before incubating at $37^{\circ} \mathrm{C}$ for $\geq 1 \mathrm{hr}$. The cultured cardiomyocytes in the 6-well tissue-culture plates were dispersed with $0.25 \%$ trypsin-EDTA and resuspended in culture medium (Maintenance Media, CDI) at $1.5 \times 10^{4}$ cells $/ \mu \mathrm{L}$. A volume of $2 \mu \mathrm{L}$ of the cell suspension was plated onto the coated area of each MED probe according to the previous study (Nakamura et al., 2014). The cells were incubated overnight at $37^{\circ} \mathrm{C}$ with $5 \% \mathrm{CO}_{2}$ in humidified conditions to promote cell attachment onto the microelectrode array, and then $1 \mathrm{~mL}$ of the culture medium was added into each chamber. The culture medium around the probe was fully replaced with fresh culture medium once a week. The cardiomyocytes were cultured for 3-5 days to form a cell sheet with spontaneous and synchronous electrical automaticity, which were used within 3 weeks after re-plating.

\section{Electrophysiological analysis of hiPSC-CMs sheets}

Prior to recording, we replaced the culture medium immersing the cardiomyocyte sheet on the MED probe. The cell sheet was re-incubated at $37^{\circ} \mathrm{C}$ in $5 \% \mathrm{CO}_{2}$ for $>30 \mathrm{~min}$, and the MED probe connected to the amplifiers (MED-A64HE1S and MED-A64MD1, Alpha MED
Scientific, Inc.) using an MED connector (MED-C03, Alpha MED Scientific, Inc.). It was then equilibrated with a gas mixture of $95 \% \mathrm{O}_{2}$ and $5 \% \mathrm{CO}_{2}$ for $30 \mathrm{~min}$ at $37^{\circ} \mathrm{C}$ on a heater (MED-CP02H, Alpha MED Scientific, Inc.) placed inside a plastic box. The cardiomyocyte sheet was electrically driven through a pair of neighboring electrodes. The stimulation pulses were biphasic, rectangular in shape, $12-50 \mu \mathrm{A}$ in amplitude (about three times the threshold current), and of $0.4 \mathrm{msec}$ duration. In this study, we selected a cycle length of 450 to $1,000 \mathrm{msec}$ (60 to $133 \mathrm{beats} / \mathrm{min}$ ) to mimic normal sinus rhythm in the human heart. The field potential duration and conduction speed were assessed with a train of 15 stimuli at a pacing cycle length of $1,000,800,700,600,500$ and $450 \mathrm{msec}$ with a pause to recover the rate of spontaneous excitation between the trains. The effective refractory period of the cardiomyocyte sheet was assessed by the programmed electrical stimulation, which consisted of 6 beats of basal stimuli at a cycle length of 1,000, 800, 700, 600, 500 and $450 \mathrm{msec}$ that was followed by an extra stimulus of various coupling intervals with a pause of $30 \mathrm{sec}$ between each sequence. The coupling interval was shortened in 5 -msec decrements until refractoriness occurred. In addition, the spontaneous excitation and its propagation across the cardiomyocyte sheet were also recorded $10 \mathrm{sec}$ prior to the stimulation.

\section{Pharmacological analysis of hiPSC-CMs sheets}

The conduction speed, field potential duration, effective refractory period and $1^{\text {st }}$ spike amplitude were assessed before and after the treatment of $\mathrm{Na}^{+}$channel blockers: disopyramide (class Ia), lidocaine (class Ib) and flecainide (class Ic); and a $\mathrm{Ca}^{2+}$ channel blocker: verapamil (class IV) (Task Force of the Working Group on Arrhythmias of the European Society of Cardiology, 1991; Vaughan Williams, 1992). The amplitude of $1^{\text {st }}$ spike was obtained as the sum of the positive and negative sharp deflections. The drugs were cumulatively administered, and the drug effects on each parameter were examined 30 min after each treatment. Each cardiomyocyte sheet received only one drug out of 4. Each field potential at 64 microelectrodes in the cell sheet were acquired. A high-pass filter of $1 \mathrm{~Hz}$ was used for assessing the effects of disopyramide, lidocaine and flecainide to stabilize the baseline, and 0.1 $\mathrm{Hz}$ was selected for analyzing that of verapamil to better examine the morphological changes in the plateau phase, whereas a low-pass filter of $5 \mathrm{kHz}$ was applied for each drug. Field potentials were digitized at a sampling rate of $20 \mathrm{kHz}$ using MED64-Basic system (Alpha MED Scientific, Inc.). 


\section{Drugs}

The following drugs were purchased: disopyramide phosphate salt (Chugai Pharmaceutical Co., Ltd., Tokyo, Japan), lidocaine (Xylocaine ${ }^{\circledR}$ Injection 2\%, AstraZeneca K.K., Osaka, Japan), flecainide acetate (Eisai Co., Ltd., Tokyo, Japan) and verapamil hydrochloride (Vasolan ${ }^{\circledR}$ for intravenous injection $5 \mathrm{mg}$, Eisai Co., Ltd.). Disopyramide and flecainide were dissolved in distilled water at a concentration of $100 \mathrm{mmol} / \mathrm{L}$, divided into aliquots, and frozen at $-20^{\circ} \mathrm{C}$. Drug solutions were diluted in distilled water on the day of experiment, and added to the cultured medium in the ratio of 1:100 to prepare the desired final concentrations. Gelatin and fibronectin were obtained from BD Biosciences (Franklin Lakes, NJ, USA). Trypsin-EDTA was purchased from Gibco ${ }^{\circledR}$, Life Technologies Japan (Tokyo, Japan).

\section{Data analyses}

Data were analyzed with Mobius software (Alpha MED Scientific, Inc.) and presented as the mean \pm S.E. The conduction speed was obtained by the following calculation: conduction speed $(\mathrm{m} / \mathrm{sec})=[$ distance between the stimulus electrode and a recording electrode (m)] / [elapsed time from an artifact of the stimulus to a negative reflection of the field potential of a recording electrode $(\mathrm{sec})]$. Each conduction speed was normalized to that for the pre-drug control at a cycle length of 1,000 msec. Statistical analysis was performed with the software GraphPad Prism 6 (ver 6.03, GraphPad Software, Inc., La Jolla, CA, USA). Statistical significances within a parameter were evaluated with repeated measures two-way analysis of variance (ANOVA) followed by the uncorrected Fisher's LSD test for mean value comparison. A $p$ value $<0.05$ was considered to be statistically significant.

\section{RESULTS}

We prepared 27 hiPSC-CMs sheets for this experiment. We selected 18 hiPSC-CMs sheets out of 27 based on their ability to be paced at control and after drug treatment; namely, 27 (100\%), 26 (96\%) and 20 (74\%) out of the 27 cell sheets were able to be electrically paced at cycle lengths of 1,000-800, 700 and $600 \mathrm{msec}$, respectively at control. We initially used 20 cell sheets which could be paced at cycle lengths of $\leq 600 \mathrm{msec}$, but 2 of them were withdrawn because of pacing failure after the administration of higher drug concentrations.

\section{Electrophysiological analysis of hiPSC-CMs sheets}

The pre-drug cycle length of spontaneous automatic- ity was $1,350 \pm 43 \mathrm{msec}(\mathrm{n}=18)$ and the pre-drug conduction speed at a pacing cycle length of 1,000 msec was $0.14 \pm 0.01 \mathrm{~m} / \mathrm{sec}(\mathrm{n}=18)$. Representative activation maps are shown in Fig. 1A (upper). The normalized conduction was significantly slowed by shortening the pacing cycle length from 1,000 to 800,700 and $600 \mathrm{msec}$ (Fig. 2A). The pre-drug effective refractory period at a cycle length of $1,000 \mathrm{msec}$ was $453 \pm 10 \mathrm{msec}(\mathrm{n}=18)$ (Fig. 2B). The effective refractory period was prolonged by shortening the pacing cycle length, and a significant difference was observed at cycle lengths between 1,000 and $600 \mathrm{msec}$. The pre-drug field potential duration at a cycle length of $1,000 \mathrm{msec}$ was $361 \pm 9 \mathrm{msec}(\mathrm{n}=18)$ (Fig. 2C). The field potential duration was significantly shortened by decreasing the pacing cycle length from 1,000 to 800,700 and $600 \mathrm{msec}$.

The cell sheets were randomized into 4 groups; namely, disopyramide group $(n=5)$, lidocaine group $(n=4)$, flecainide group $(n=5)$ and verapamil group $(n=4)$. There was no significant difference among the 4 groups in any of the pre-drug control values of conduction speed, effective refractory period or field potential duration at cycle lengths of 1,000, 800, 700 or $600 \mathrm{msec}$. In addition, coefficient of variance was $8 \sim 16,0 \sim 12,2 \sim 15$ and $2 \sim 20$ in the cycle length of spontaneous automaticity, conduction speed, effective refractory period and field potential duration at pre-drug control, respectively, indicating small variability among the cell sheets.

\section{Electropharmacological analysis of hiPSC-CMs sheets}

\section{Spontaneous automaticity}

Effects of $\mathrm{Na}^{+}$and $\mathrm{Ca}^{2+}$ channel blockers on the cycle length of the spontaneous automaticity of the cell sheets are summarized in Table 1. Disopyramide tended to prolong the cycle length, which did not achieve statistical significance. Lidocanine and flecainide prolonged it in a concentration-related manner, and significant changes were detected at 3 and $0.1-1 \mu \mathrm{mol} / \mathrm{L}$, respectively. In contrast, verapamil shortened it in a concentration-related manner, and significant changes were detected at 0.03-1 $\mu \mathrm{mol} / \mathrm{L}$.

\section{Conduction}

Representative activation maps before (Control) and after the drug treatment are depicted in Fig. 1A. Disopyramide and lidocaine slowed the conduction in a concentration-related manner, and a significant change was detected at $3 \mu \mathrm{mol} / \mathrm{L}$ for both drugs (Fig. 3 top). Flecainide slightly accelerated the conduction at $0.03-0.1 \mu \mathrm{mol} / \mathrm{L}$, 
A Disopyramide Lidocaine

Flecainide Verapamil
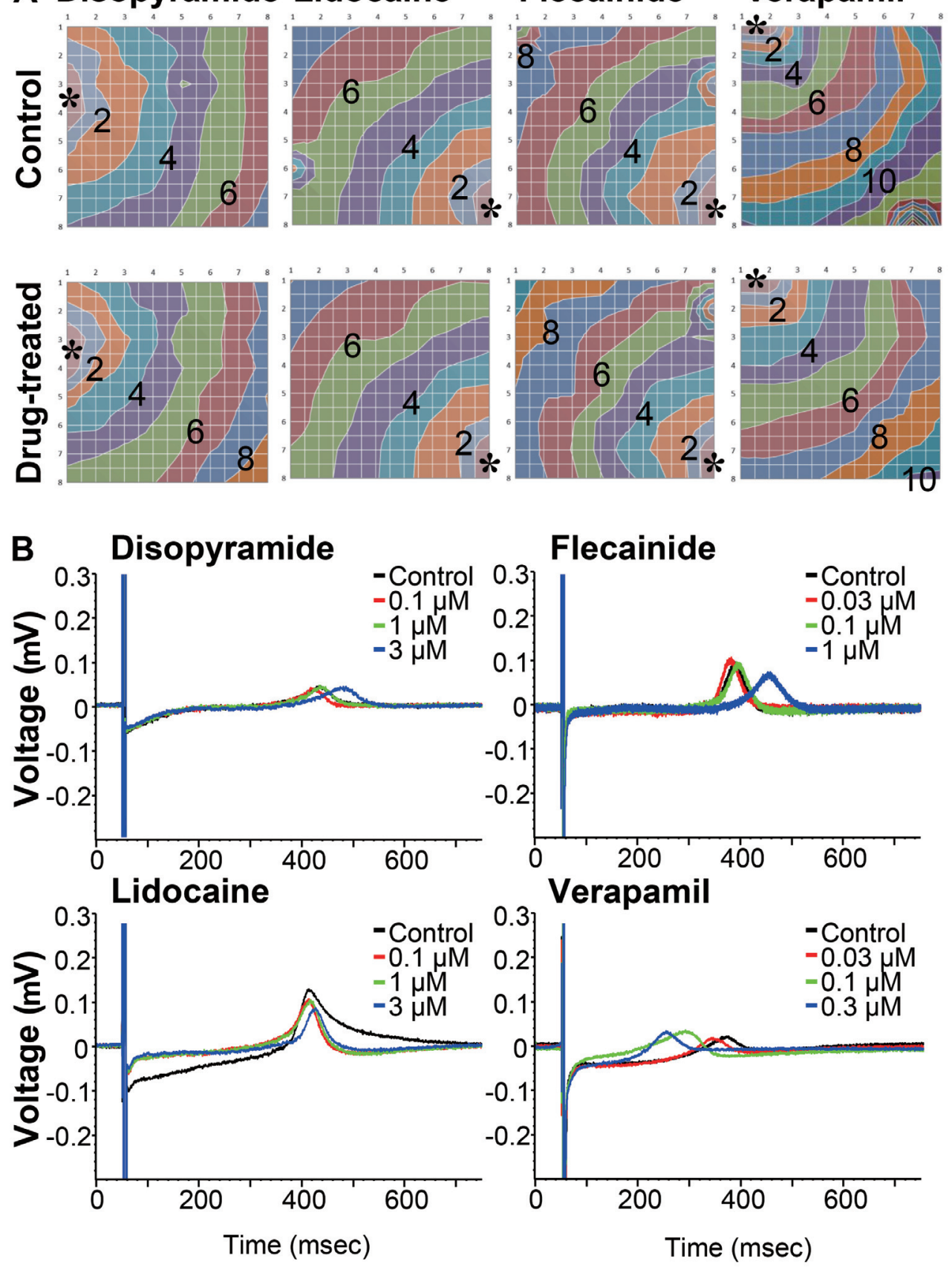

Fig. 1. Representative activation maps and field potential waveforms during electrical stimulation. A: Representative activation maps of human induced pluripotent stem cell-derived cardiomyocytes sheets are shown at pre-drug control (Control, upper) and after the treatment of the drugs (Drug-treated, lower): namely, 3 of disopyramide and lidocaine, 1 of flecainide and $0.3 \mu \mathrm{mol} / \mathrm{L}$ of verapamil. Asterisks on each map show the region where field electrical stimulation was applied through a pair of electrodes. The numbers on isochrones indicate the elapsed time $(\mathrm{msec})$ from an artifact of the 15 th electrical stimulus to a negative deflection of $1^{\text {st }}$ spike of the field potential of each recording electrode at a basic cycle length of $800 \mathrm{msec}$ for disopyramide, lidocaine and flecainide and $600 \mathrm{msec}$ for verapamil. It took $8-12 \mathrm{msec}$ to conduct across the cardiomyocyte sheet in an area of $1.05 \times 1.05 \mathrm{~mm}$. B: Representative waveforms of field potential of the last excitation during a train of 15 stimuli at a cycle length of $800 \mathrm{msec}$ for disopyramide, lidocaine and flecainide and $600 \mathrm{msec}$ for verapamil are shown before and after the treatment of drugs. 

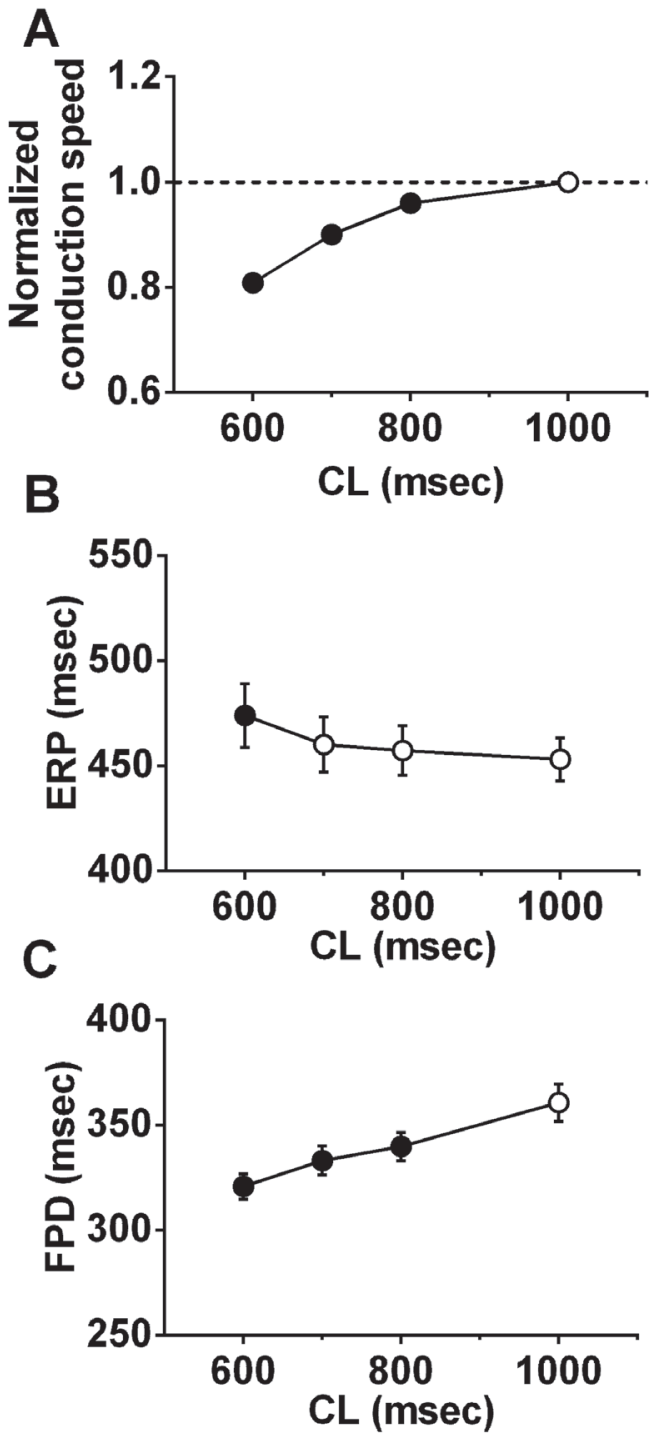

Fig. 2. The basal characteristics of human induced pluripotent stem cell-derived cardiomyocytes sheets during electrical stimulation at a basic pacing cycle length (CL) of 600-1,000 msec. A: Normalized conduction speed. Conduction speeds at pacing cycle lengths of $600-800 \mathrm{msec}$ were normalized by the value at a cycle length of 1,000 msec in each cell sheet. B: Effective refractory period (ERP). C: field potential duration (FPD). Closed symbols indicate that the value is significantly different from that at a basic pacing cycle length of $1,000 \mathrm{msec}$. Data are presented as the mean \pm S.E. $(\mathrm{n}=18)$.

but slowed it at $1 \mu \mathrm{mol} / \mathrm{L}$. Verapamil enhanced the conduction in a concentration-related manner, and significant changes were detected at $0.03-0.3 \mu \mathrm{mol} / \mathrm{L}$. We could not pace the cell sheets at a cycle length of $600 \mathrm{msec}$ after
1-3 $\mu \mathrm{mol} / \mathrm{L}$ of disopyramide, at cycle lengths of $600-700$ msec after $1 \mu \mathrm{mol} / \mathrm{L}$ of flecainide, and at cycle lengths of $600-1,000 \mathrm{msec}$ after $1 \mu \mathrm{mol} / \mathrm{L}$ of verapamil.

\section{Effective refractory period}

Disopyramide, lidocaine and flecainide prolonged the effective refractory periods in a concentration-related manner, and significant changes were detected at 0.1-3 of disopyramide, 1-3 of lidocaine and 0.03-1 $\mu \mathrm{mol} / \mathrm{L}$ of flecainide (Fig. 3 middle upper). Meanwhile, verapamil shortened the effective refractory period in a concentration-related manner, and significant changes were detected at $0.03-0.3 \mu \mathrm{mol} / \mathrm{L}$.

\section{Field potential duration}

Representative traces of field potential changes before and after the drug treatment were overlaid as shown in Fig. 1B. Disopyramide, lidocaine and flecainide prolonged the field potential duration in a concentration-related manner, and significant changes were detected at 1-3 of disopyramide, $0.1-3$ of lidocaine and 0.1-1 $\mu \mathrm{mol} / \mathrm{L}$ of flecainide (Fig. 3 middle lower). Meanwhile, verapamil shortened the field potential duration in a concentrationrelated manner, and significant changes were detected at $0.03-0.3 \mu \mathrm{mol} / \mathrm{L}$.

\section{First spike amplitude}

Disopyramide increased the normalized $1^{\text {st }}$ spike amplitude at $0.1-1 \mu \mathrm{mol} / \mathrm{L}$ at each pacing cycle length, but decreased it at $3 \mu \mathrm{mol} / \mathrm{L}$ at a pacing cycle length of $700 \mathrm{msec}$ (Fig. 3 bottom). Lidocaine increased it at $0.1-3 \mu \mathrm{mol} / \mathrm{L}$. Flecainide increased it at $0.1 \mu \mathrm{mol} / \mathrm{L}$ at a pacing cycle length of $1,000 \mathrm{msec}$, but decreased it at $600 \mathrm{msec}$. Similarly, flecainide increased it at $1 \mu \mathrm{mol} / \mathrm{L}$ at a pacing cycle length of $1,000 \mathrm{msec}$, but decreased it at $800 \mathrm{msec}$. Verapamil increased it at $0.03-0.1 \mu \mathrm{mol} / \mathrm{L}$ at pacing cycle lengths of 700-600 msec.

\section{DISCUSSION}

By using the programmed electrical stimulation protocol, in this study we precisely analyzed the basal electrophysiological properties of the hiPSC-CMs sheet as well as the electropharmacological effects of $\mathrm{Na}^{+}$and $\mathrm{Ca}^{2+}$ channel blockers on them within the physiological human heart rate for the first time. We found the cell sheet exerted essentially the same responses during electrophysiological and pharmacological interventions as those expected in the human heart; although there were some differences between them as discussed below. 
Table 1. Effects of $\mathrm{Na}^{+}$and $\mathrm{Ca}^{2+}$ channel blockers on the spontaneous automaticity in the human induced pluripotent stem cell-derived cardiomyocytes sheets.

\begin{tabular}{lcccc}
\hline$\mu \mathrm{M}$ & \multicolumn{4}{c}{ Cycle length of spontaneous automaticity $(\mathrm{msec})$} \\
\cline { 2 - 5 } & Disopyramide $(\mathrm{n}=5)$ & Lidocaine $(\mathrm{n}=4)$ & Flecainide $(\mathrm{n}=5)$ & Verapamil $(\mathrm{n}=4)$ \\
\hline 0 & $1,379 \pm 112$ & $1,215 \pm 48$ & $1,384 \pm 100$ & $1,404 \pm 97$ \\
0.03 & - & - & $1,415 \pm 90$ & $1,259 \pm 68^{*}$ \\
0.1 & $1,407 \pm 121$ & $1,246 \pm 63$ & $1,472 \pm 94^{*}$ & $954 \pm 56^{*}$ \\
0.3 & - & - & - & $752 \pm 42^{*}$ \\
1 & $1,401 \pm 136$ & $1,277 \pm 74$ & $1,575 \pm 82^{*}$ & $640 \pm 39^{*}$ \\
3 & $1,448 \pm 128$ & $1,329 \pm 79^{*}$ & - & - \\
\hline
\end{tabular}

Data are represented as the mean \pm S.E. ${ }^{*} p$ value $<0.05$, compared with the respective pre-drug control value $(=0 \mu \mathrm{M})$ within a group.

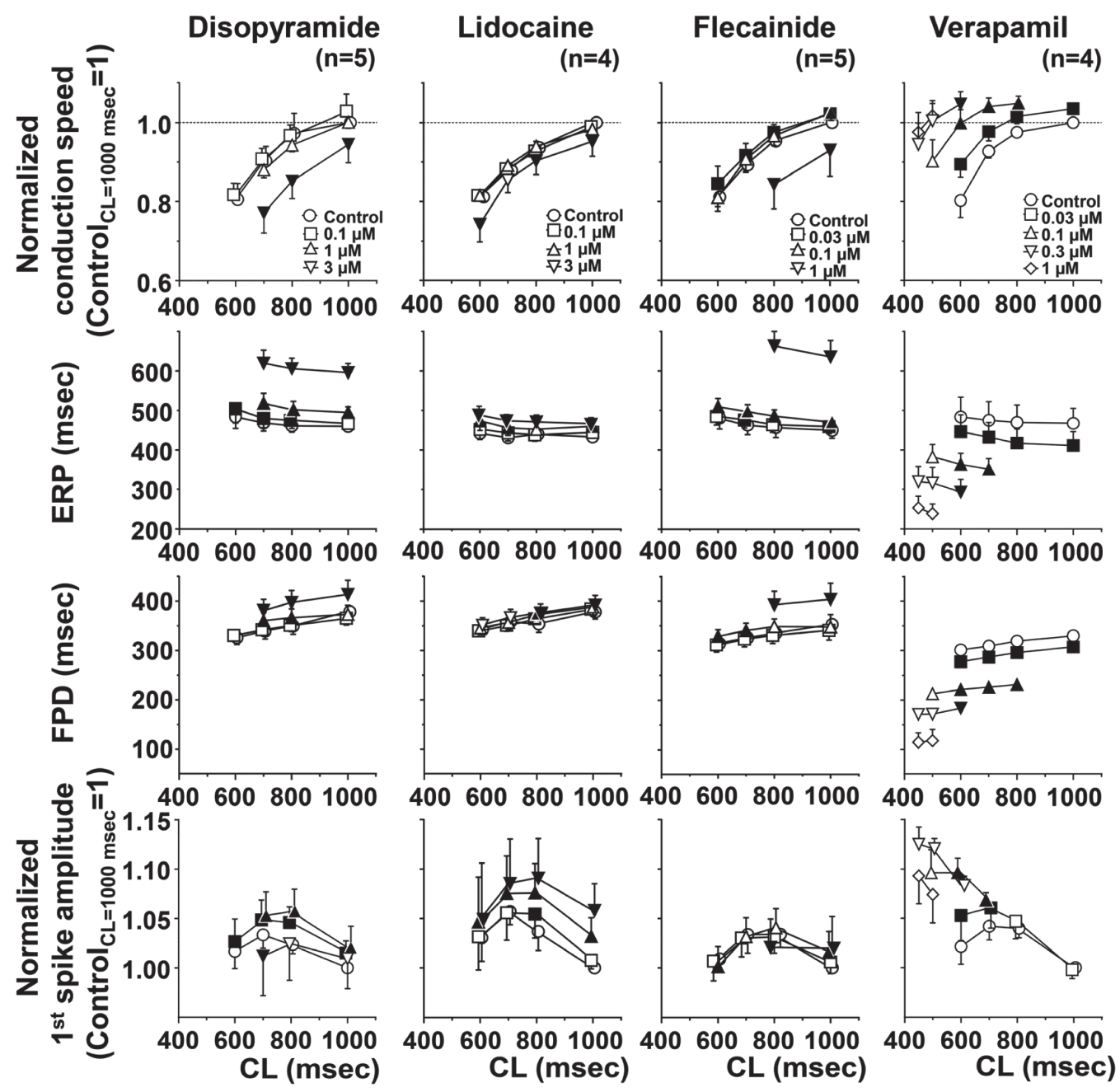

Fig. 3. The effects of disopyramide, lidocaine, flecainide and verapamil on the normalized conduction speed, effective refractory period (ERP), field potential duration (FPD) and normalized $1^{\text {st }}$ spike amplitude. Conduction speed and $1^{\text {st }}$ spike amplitude were normalized by the pre-drug controls at a pacing cycle length (CL) of 1,000 msec. Closed symbols indicate that the value is significantly different from the pre-drug control at the same pacing cycle length. Data are presented as the mean \pm S.E. 


\section{The field potential duration of hiPSC-CMs sheets}

The field potential duration of the cell sheet was $361 \pm 9 \mathrm{msec}$ at the pacing cycle length of $1,000 \mathrm{msec}$ $(\mathrm{n}=18)$ (Fig. 2C). The shortening of pacing cycle length from 1,000 to $600 \mathrm{msec}$ abbreviated the field potential duration, which was similar to that reported in the in situ intact humans heart (Josephson, 1993). Ma et al. (2011) analyzed the membrane potential of single iCell Cardiomyocytes (CDI) by using perforated patch-clamp techniques to classify the cells according to their action potential waveforms, in which the average action potential duration at $90 \%$ repolarization was $255 \mathrm{msec}$ in nodaltype, $286 \mathrm{msec}$ in atrial-type and $415 \mathrm{msec}$ in ventriculartype. Asakura et al. (2015) simultaneously recorded the field potential and membrane potential of hiPSC-CMs, and found that end of the field potential duration corresponded to the action potential duration at $50 \%$ repolarization level. Since the field potential duration observed in this study was close to the action potential duration of the ventricular-type single iCell Cardiomyocyte (Ma et al., 2011), a large population of cells in our sheets can be considered to be ventricular-type.

The action potential duration of ventricular muscle cells in humans was reported to be 200-300 msec (Fozzard and Arnsdorf, 1992), which would be much shorter than that estimated from our study. It was reported that expression levels of genes of $\mathrm{KCNH} 2, \mathrm{KCNE} 2$ and $K C N Q 1$ were higher in hiPSC-CMs than those in the human adult heart, whereas that of $K C N E 1$ was similar between them (Uesugi et al., 2014). In addition, the extent of expression of a gene SLC8A1 encoding $\mathrm{Na}^{+} /$ $\mathrm{Ca}^{2+}$ exchanger 1 (NCX1) has been reported to be similar between adult heart tissue and structured hiPSC-CMs (Rao et al., 2013). Meanwhile, inward rectifier $\mathrm{K}^{+}$current $\left(\mathrm{I}_{\mathrm{K} 1}\right)$ was shown to be hardly expressed in the hiPSC-CMs (Ma et al., 2011; Doss et al., 2012; Meijer van Putten et al., 2015; Uesugi et al., 2014). Since $\mathrm{I}_{\mathrm{K} 1}$ plays an important role in the repolarization process in phase 3 (Meijer van Putten et al., 2015), the low current density of $\mathrm{I}_{\mathrm{K} 1}$ may partly explain the long field potential duration of the cell sheet in this study.

\section{Effects of $\mathrm{Na}^{+}$channel blockers on the electrophysiological variables}

Disopyramide and lidocaine slowed conduction in a concentration-related manner. Meanwhile, contrary to our expectation, flecainide accelerated it at $0.03-0.1 \mu \mathrm{mol} / \mathrm{L}$ but slowed it at $1 \mu \mathrm{mol} / \mathrm{L}$ (Fig. 3 top). Flecainide at concentrations of 10 and $100 \mu \mathrm{mol} / \mathrm{L}$ inhibited L-type $\mathrm{Ca}^{2+}$ channel current in canine ventricular myocytes by $25 \pm 6$ and $65 \pm 10 \%$, respectively (Kihara et al., 1996), suggest- ing that L-type $\mathrm{Ca}^{2+}$ channel inhibition may have partly played a role in the observed conduction acceleration as observed for verapamil in this study, which needs to be elucidated. These drugs prolonged the effective refractory period of the cell sheet in a concentration-related manner (Fig. 3 middle upper). Since $\mathrm{IC}_{50}$ values of $\mathrm{I}_{\mathrm{Na}}$ for resting state were reported to be $158 \pm 11$ for disopyramide, 606 \pm 15 for lidocaine and $50.8 \pm 11.5 \mu \mathrm{mol} / \mathrm{L}$ for flecainide (Wang et al., 2013), current results at least suggest that conduction in the cell sheet may largely depend on $\mathrm{Na}^{+}$ channel availability like that in the human ventricle.

Each drug prolonged the field potential duration in a concentration-related manner, extent of which was the smallest in lidocaine-treated sheets (Fig. 3 middle lower). The $\mathrm{IC}_{50}$ values of the human ether-à-go-go-related gene ( $h E R G) \mathrm{K}^{+}$channel have been reported to be 7.2-10.7 for disopyramide, 262.9 for lidocaine and $3.9 \mu \mathrm{mol} / \mathrm{L}$ for flecainide at $35-37^{\circ} \mathrm{C}$ (Polak et al., 2009), which may partly explain the difference in the extent of prolongation of field potential duration. It should be noted that the result for lidocaine was directionally different from that in the in situ human heart, in which the QT interval was shortened via late $\mathrm{Na}^{+}$current inhibition (Johannesen et al., 2016). Thus, the constitutively active late $\mathrm{Na}^{+}$current may be hardly expressed in the cell sheet unlike the human heart.

Contrary to our expectation based on the previous knowledge; namely, the $1^{\text {st }}$ spike amplitude of field potentials reflects the $\mathrm{Na}^{+}$influx during the depolarization phase of the ventricular action potential (Fozzard and Arnsdorf, 1992), there was no relationship between the conduction delay and $1^{\text {st }}$ spike amplitude reduction after the treatment of $\mathrm{Na}^{+}$channel blockers (Fig. 3 bottom).

\section{Effects of verapamil on the electrophysiological variables}

Verapamil at $0.03 \mu \mathrm{mol} / \mathrm{L}$ shortened the field potential duration by $23 \mathrm{msec}$ in the cell sheet, at a cycle length of $1,000 \mathrm{msec}$ (Fig. 3 middle lower). This result is quite different from a previous report in humans by Johannesen et al. (Johannesen et al., 2014), describing that verapamil hardly altered the corrected QT interval by Fridericia's formula at a peak plasma concentration of $130 \pm 76 \mathrm{ng} / \mathrm{mL}$ $(0.270 \mu \mathrm{mol} / \mathrm{L})$. The $\mathrm{IC}_{50}$ values of verapamil for $\mathrm{Na}^{+}$, L-type $\mathrm{Ca}^{2+}$ and $h E R G \mathrm{~K}^{+}$channels have been reported to be 4.272, 0.333 and $0.201 \mu \mathrm{mol} / \mathrm{L}$ (Okada et al., 2015), respectively. Moreover, a selective L-type $\mathrm{Ca}^{2+}$ channel blocker nifedipine and a specific $h E R G \mathrm{~K}^{+}$channel blocker E-4031 have been demonstrated to shorten and prolong the field potential duration, respectively in hiPSCCMs sheets (Harris et al., 2013). In addition, verapamil has been reported to block cardiac L-type $\mathrm{Ca}^{2+}$ chan- 


\section{H. Izumi-Nakaseko et al.}

nels in a frequency- and use-dependent manner (Nawrath and Wegener, 1997), whereas drug-induced inhibition of the rapidly activating delayed-rectifier $\mathrm{K}^{+}$current $\left(\mathrm{I}_{\mathrm{Kr}}\right)$ is known to be enhanced in a reverse use-dependent manner (Yang and Roden, 1996). Since verapamil increased the automaticity rate of the cell sheet, the effects of verapamil on the field potential duration were assessed at relatively faster beating rate. It might have enhanced inhibition of L-type $\mathrm{Ca}^{2+}$ channels, but reduced the extent of $\mathrm{I}_{\mathrm{Kr}}$ inhibition, explaining the verapamil-mediated abbreviation of field potential duration.

Verapamil shortened the effective refractory period and accelerated conduction (Fig. 3 top and middle upper), latter of which has been reported in the accessory pathway in patients with Wolff-Parkinson-White syndrome (Harper et al., 1982). The shortening of the field potential duration by verapamil (Fig. 3 middle lower) may not only abbreviate the effective refractory period but also enhance the recovery period of $\mathrm{Na}^{+}$channels, leading to the acceleration of conduction, which could be reflected in the increase of the $1^{\text {st }}$ spike amplitude (Fig. 3 bottom). Moreover, these results suggest that the conduction may not depend on L-type $\mathrm{Ca}^{2+}$ channel availability in the cell sheet.

\section{Relationship between $\mathrm{Na}^{+}$channel availability and conduction}

At the pacing cycle length of $1,000 \mathrm{msec}(\mathrm{n}=18)$, the conduction speed of excitations in the cell sheets $(0.14 \pm 0.01 \mathrm{~m} / \mathrm{sec})$ was approximately half of that in the intact human ventricle $(0.2-0.3 \mathrm{~m} / \mathrm{sec})$ (Levy and Pappano, 2007). Also, the effective refractory period of the cell sheet $(453 \pm 10 \mathrm{msec})$ was longer than that in the human right ventricle (170-290 msec) (Josephson, 1993). Conduction speed of two-dementional cell sheet consisting of hiPSC-CMs has been reported to be 0.041-0.056 $\mathrm{m} / \mathrm{sec}$ (Kadota et al., 2013), $0.22 \pm 0.02 \mathrm{~m} / \mathrm{sec}$ (Lee et al., 2012) and $\sim 0.15 \mathrm{~m} / \mathrm{sec}$ (Nunes et al., 2013), indicating that conduction speed in our cell sheets can be comparable to others'. Shortening of the pacing cycle length from 1,000 down to $600 \mathrm{msec}$ prolonged the effective refractory period but slowed the conduction in the cell sheet at the pre-drug control (Figs. 2A and 2B), which were opposite to the previous observation in the intact human heart (Josephson, 1993; Ward et al., 1979). $\mathrm{V}_{1 / 2}$ for steadystate inactivation of cardiac $\mathrm{Na}^{+}$channel (Nav1.5) has been reported to be $-84 \mathrm{mV}$ (Wang et al., 2015). Maximum diastolic potential in single hiPSC-CM ranged from -75 to $-60 \mathrm{mV}$ (Ma et al., 2011), whereas that in the human ventricle was $-87 \mathrm{mV}$ (Trautwein et al., 1962), suggesting that steady-state inactivation of $\mathrm{Na}^{+}$chan- nels may be enhanced in the cell sheet. In addition, since a long depolarization pulse could delay the recovery of Nav1.5 channels from inactivation (Ramos and O'leary, 2004), the long action potential duration in the cell sheet might have slowed the recovery of $\mathrm{Na}^{+}$channels; thus, facilitating $\mathrm{Na}^{+}$channel inactivation, which may explain the frequency-dependent conduction delay and effective refractory period prolongation in this study. This hypothesis can be indirectly supported by the results of verapamil, in which conduction was accelerated concomitantly with the shortening of field potential duration and effective refractory period.

\section{Automaticity of the cell sheet}

Verapamil enhanced the automaticity of the cell sheet by $120 \%$, whereas flecainide and lidocaine suppressed it by 12 and $9 \%$, respectively; and disopyramide tended to suppress it by $5 \%$, extent of which was in parallel with the $\mathrm{IC}_{50}$ value of $\mathrm{I}_{\mathrm{Na}}$ for open state; namely, $0.63 \pm 0.06$ for flecainide, $35.3 \pm 2.7$ for lidocainie and $52.5 \pm 2.8 \mu \mathrm{mol} / \mathrm{L}$ for disopyramide (Wang et al., 2013). Thus, upstroke of action potentials in the cell sheet during spontaneous automaticity is considered to be mediated by $\mathrm{Na}^{+}$channel current rather than L-type $\mathrm{Ca}^{2+}$ channel current like in the idioventricular rhythm in Purkinje fibers (Abete et al., 1991; Sugiyama et al., 1994), although iCell Cardiomyocytes (CDI) have been reported to contain a small number of nodal-type cells (Ma et al., 2011).

\section{Limitation}

Calcium imaging, membrane potential recording with voltage sensitive dye and field potential recording have respective advantage and disadvantage in testing conduction speed. Calcium imaging can show the intracellular $\mathrm{Ca}^{2+}$ dynamics, which may be directly linked to contraction of the cells; however, the contractile movement of cell sheet is usually restricted to obtain better images, and the breaching of fluorescence dye limits the observation period. Membrane potential recording with voltage sensitive dye can record the action potential waveform changes, and map the macroscopic conduction wavefront, but the breaching of fluorescence dye limits the observation period like calcium imaging. The field potential recording can obtain indirect information on electrical excitation of cells, but it may monitor the conduction properties continuously for minutes to days without any modification.

It should be also noted that some differences in drug responses between the cell sheets and the human ventricle were observed. For example, lidocaine prolonged the field potential duration; and verapamil shortened the field potential duration and effective refractory period and 
enhanced the conduction in the cell sheets. Thus, caution should be taken in the evaluation of multi-channel blockers with the cell sheet.

In conclusion, the cell sheets exerted essentially the same responses to those expected in the human ventricle during electrophysiological and electropharmacological interventions; namely, conduction as well as spontaneous automaticity of the cell sheet may largely depend on the extent of $\mathrm{Na}^{+}$channel availability. Importantly, there was no relationship between the conduction delay and $1^{\text {st }}$ spike amplitude reduction after the treatment of $\mathrm{Na}^{+}$channel blockers. These findings may provide crucial guide on future application of this new technology for early phase safety pharmacological screening of new chemical entities.

\section{ACKNOWLEDGMENTS}

This work was supported by the Project Research Grant of Toho University Graduate School of Medicine (No. 25-4, 26-16; to HI-N); the Fund for the Advancement of Science in commemoration of Toho University's 60th anniversary (to HI-N); Grants-in-Aid for Scientific Research from the Ministry of Education, Culture, Sports, Science and Technology in Japan JSPS KAKENHI (16K08559; to AS); the Research on Regulatory Harmonization and Evaluation of Pharmaceuticals, Medical Devices, Regenerative and Cellular Therapy Products, Gene Therapy Products, and Cosmetics from the Japan Agency for Medical Research and Development AMED Grant (15mk0104053h0101, 16mk0104027j0002; to YS): and Initiative for Realizing Diversity in the Research Environment (to HI-N). The authors thank Ms. Misako Nakatani and Yuri Ichikawa for their technical assistance, and Alpha MED Scientific, Inc. and iPS PORTAL, Inc. for their technical advice.

Conflict of interest---- The authors declare that there is no conflict of interest.

\section{REFERENCES}

Abete, P., Ferrara, N., Rengo, F. and Vassalle, M. (1991): Mechanisms of lidocaine actions on normal and abnormal rhythms in canine cardiac tissues in vivo and in vitro. Clin. Exp. Pharmacol. Physiol., 18, 179-191.

Asakura, K., Hayashi, S., Ojima, A., Taniguchi, T., Miyamoto, N., Nakamori, C., Nagasawa, C., Kitamura, T., Osada, T., Honda, Y., Kasai, C., Ando, H., Kanda, Y., Sekino, Y. and Sawada, K. (2015): Improvement of acquisition and analysis methods in multi-electrode array experiments with iPS cell- derived cardiomyocytes. J. Pharmacol. Toxicol. Methods., 75, 17-26.

Doss, M.X., Di Diego, J.M., Goodrow, R.J., Wu, Y., Cordeiro, J.M., Nesterenko, V.V., Barajas-Martínez, H., Hu, D., Urrutia, J., Desai, M., Treat, J.A., Sachinidis, A. and Antzelevitch, C. (2012): Maximum diastolic potential of human induced pluripotent stem cell-derived cardiomyocytes depends critically on $\mathrm{I}_{\mathrm{Kr}}$. PLoS One, 7, e40288.

Fozzard, H.A. and Arnsdorf, M.F. (1992): Cardiac electrophysiology, In The Heart and Cardiovascular System: Scientific Foundations. 2nd ed. (Fozzard, H.A., Haber, E., Katz, A.M., Morgan, H.A. and Jennings, R.B. eds), pp.99-110, Raven Press, New York

Gibson, J.K., Yue, Y., Bronson, J., Palmer, C. and Numann, R. (2014): Human stem cell-derived cardiomyocytes detect drugmediated changes in action potentials and ion currents. J. Pharmacol. Toxicol. Methods, 70, 255-267.

Harper, R.W., Whitford, E., Middlebrook, K., Federman, J., Anderson, S. and Pitt, A. (1982): Effects of verapamil on the electrophysiologic properties of the accessory pathway in patients with the Wolff-Parkinson-White syndrome. Am. J. Cardiol., 50, 1323-1330.

Harris, K., Aylott, M., Cui, Y., Louttit, J.B., McMahon, N.C. and Sridhar, A. (2013): Comparison of electrophysiological data from human-induced pluripotent stem cell-derived cardiomyocytes to functional preclinical safety assays. Toxicol. Sci., 134, $412-426$.

Johannesen, L., Vicente, J., Mason, J.W., Sanabria, C., Waite-Labott, K., Hong, M., Guo, P., Lin, J., Sørensen, J.S., Galeotti, L., Florian, J., Ugander, M., Stockbridge, N. and Strauss, D.G. (2014): Differentiating drug-induced multichannel block on the electrocardiogram: randomized study of dofetilide, quinidine, ranolazine, and verapamil. Clin. Pharmacol. Ther., 96, 549-558.

Johannesen, L., Vicente, J., Mason, J.W., Erato, C., Sanabria, C., Waite-Labott, K., Hong, M, Lin, J., Guo, P., Mutlib, A., Wang, J., Crumb, W.J., Blinova, K., Chan, D., Stohlman, J., Florian, J., Ugander, M., Stockbridge, N. and Strauss, D.G. (2016): Late sodium current block for drug-induced long QT syndrome: Results from a prospective clinical trial. Clin. Pharmacol. Ther., 99, 214-223.

Josephson, M.E. (1993): Electrophysiological investigation: General concepts, In Clinical Cardiac Electrophysiology: Techniques and Interpretations. 2nd ed. (Josephson, M.E., ed.), pp.22-70, Lea \& Febiger, Philadelphia.

Kadota, S., Minami, I., Morone, N., Heuser, J.E., Agladze, K. and Nakatsuji, N. (2013): Development of a reentrant arrhythmia model in human pluripotent stem cell-derived cardiac cell sheets. Eur. Heart J., 34, 1147-1156.

Kihara, Y., Inoko, M., Hatakeyama, N., Momose, Y. and Sasayama, S. (1996): Mechanisms of negative inotropic effects of class Ic antiarrhythmic agents: comparative study of the effects of flecainide and pilsicainide on intracellular calcium handling in dog ventricular myocardium. J. Cardiovasc. Pharmacol., 27, 42-51.

Lee, P., Klos, M., Bollensdorff, C., Hou, L., Ewart, P., Kamp, T.J., Zhang, J., Bizy, A., Guerrero-Serna, G., Kohl, P., Jalife, J. and Herron, T.J. (2012): Simultaneous voltage and calcium mapping of genetically purified human induced pluripotent stem cell-derived cardiac myocyte monolayers. Circ. Res., 110, 1556-1563.

Levy, M.N. and Pappano, A.J. (2007), Automaticity: Natural excitation of the heart, In Cardiovascular Physiology. 9th ed. (Levy, M.N. and Pappano, A.J., eds.), pp.33-54, Mosby, Inc, Philadelphia. 


\section{H. Izumi-Nakaseko et al.}

Ma, J., Guo, L., Fiene, S.J., Anson, B.D., Thomson, J.A., Kamp, T.J., Kolaja, K.L., Swanson, B.J. and January, C.T. (2011): High purity human-induced pluripotent stem cell-derived cardiomyocytes: electrophysiological properties of action potentials and ionic currents. Am. J. Physiol. Heart Circ. Physiol., 301, H2006H2017.

Mehta, A., Chung, Y., Sequiera, G.L., Wong, P., Liew, R. and Shim, W. (2013): Pharmacoelectrophysiology of viral-free induced pluripotent stem cell-derived human cardiomyocytes. Toxicol. Sci., 131, 458-469.

Meijer van Putten, R.M., Mengarelli, I., Guan, K., Zegers, J.G., van Ginneken, A.C., Verkerk, A.O. and Wilders, R. (2015): Ion channelopathies in human induced pluripotent stem cell derived cardiomyocytes: a dynamic clamp study with virtual $\mathrm{I}_{\mathrm{K} 1}$. Front. Physiol., 6, 7.

Miller, J.M. and Zipes, D.P. (2008): Diagnosis of cardiac arrhythmias. In Braunwald's Heart Disease. 8th ed. (Libby, P., Bonow, R.O., Mmann, D.L., Zipes, D.P. and Braunwald, E., eds.), pp.763-778, Saunders, Philadelphia.

Nakamura, Y., Matsuo, J., Miyamoto, N., Ojima, A., Ando, K., Kanda, Y., Sawada, K., Sugiyama, A. and Sekino, Y. (2014): Assessment of testing methods for drug-induced repolarization delay and arrhythmias in an iPS cell-derived cardiomyocyte sheet: multi-site validation study. J. Pharmacol. Sci., 124, 494501.

Navarrete, E.G., Liang, P., Lan, F., Sanchez-Freire, V., Simmons, C., Gong, T., Sharma, A., Burridge, P.W., Patlolla, B., Lee, A.S., Wu, H., Beygui, R.E., Wu, S.M., Robbins, R.C., Bers, D.M. and Wu, J.C. (2013): Screening drug-induced arrhythmia using human induced pluripotent stem cell-derived cardiomyocytes and lowimpedance microelectrode arrays. Circulation, 128, S3-S13.

Nawrath, H. and Wegener, J.W. (1997): Kinetics and state-dependent effects of verapamil on cardiac L-type calcium channels. Naunyn. Schmiedebergs. Arch. Pharmacol., 355, 79-86.

Nozaki, Y., Honda, Y., Tsujimoto, S., Watanabe, H., Kunimatsu, T. and Funabashi, H. (2014): Availability of human induced pluripotent stem cell-derived cardiomyocytes in assessment of drug potential for QT prolongation. Toxicol. Appl. Pharmacol., 278, $72-77$.

Nunes, S.S., Miklas, J.W., Liu, J., Aschar-Sobbi, R., Xiao, Y., Zhang, B., Jiang, J., Massé, S., Gagliardi, M., Hsieh, A., Thavandiran, N., Laflamme, M.A., Nanthakumar, K., Gross, G.J., Backx, P.H., Keller, G. and Radisic, M. (2013): Biowire: a new platform for maturation of human pluripotent stem cellderived cardiomyocytes. Nat. Methods., 10, 781-787.

Okada, J., Yoshinaga, T., Kurokawa, J., Washio, T., Furukawa, T., Sawada, K., Sugiura, S. and Hisada, T. (2015): Screening system for drug-induced arrhythmogenic risk combining a patch clamp and heart simulator. Sci. Adv., 1, e1400142.

Peng, S., Lacerda, A.E., Kirsch, G.E., Brown, A.M. and
Bruening-Wright, A. (2010): The action potential and comparative pharmacology of stem cell-derived human cardiomyocytes. J. Pharmacol. Toxicol. Methods., 61, 277-286.

Polak, S., Wiśniowska, B. and Brandys, J. (2009): Collation, assessment and analysis of literature in vitro data on $\mathrm{hERG}$ receptor blocking potency for subsequent modeling of drugs' cardiotoxic properties. J. Appl. Toxicol., 29, 183-206.

Ramos, E. and O'leary, M.E. (2004): State-dependent trapping of flecainide in the cardiac sodium channel. J. Physiol., 560, 37-49.

Rao, C., Prodromakis, T., Kolker, L., Chaudhry, U.A., Trantidou, T., Sridhar, A., Weekes, C., Camelliti, P., Harding, S.E., Darzi, A., Yacoub, M.H., Athanasiou, T. and Terracciano, C.M. (2013): The effect of microgrooved culture substrates on calcium cycling of cardiac myocytes derived from human induced pluripotent stem cells. Biomaterials, 34, 2399-2411.

Sugiyama, A., Motomura, S. and Hashimoto, K. (1994): Utilization of an isolated, blood-perfused canine papillary muscle preparation as a model to assess efficacy and adversity of class I antiarrhythmic drugs. Jpn. J. Pharmacol., 66, 303-316.

Task Force of the Working Group on Arrhythmias of the European Society of Cardiology. (1991): The Sicilian gambit. A new approach to the classification of antiarrhythmic drugs based on their actions on arrhythmogenic mechanisms. Circulation, 84, 1831-1851.

Trautwein, W., Kassebaum, D.G., Nelson, R.M. and Hecht, H.H. (1962): Electrophysiological study of human heart muscle. Circ. Res., 10, 306-312.

Uesugi, M., Ojima, A., Taniguchi, T., Miyamoto, N. and Sawada, K. (2014): Low-density plating is sufficient to induce cardiac hypertrophy and electrical remodeling in highly purified human iPS cell-derived cardiomyocytes. J. Pharmacol. Toxicol. Methods., 69, 177-188.

Vaughan Williams, E.M. (1992): The relevance of cellular to clinical electrophysiology in classifying antiarrhythmic actions. J. Cardiovasc. Pharmacol., 20 Suppl 2, S1-S7. Review.

Wang, G.K., Russell, G. and Wang, S.Y. (2013): Persistent human cardiac $\mathrm{Na}^{+}$currents in stably transfected mammalian cells: Robust expression and distinct open-channel selectivity among Class 1 antiarrhythmics. Channels., 7, 263-274.

Wang, Y., Mi, J., Lu, K., Lu, Y. and Wang, K. (2015): Comparison of gating properties and use-dependent block of Nav1.5 and Nav1.7 channels by anti-arrhythmics mexiletine and lidocaine. PLoS One., 10, e0128653.

Ward, D.E., Camm, A.J. and Spurrell, R.A. (1979): Patterns of atrial activation during right ventricular pacing in patients with concealed left-sided Kent pathways. Br. Heart J., 42, 192-200.

Yang, T. and Roden, D.M. (1996): Extracellular potassium modulation of drug block of $\mathrm{I}_{\mathrm{Kr}}$. Implications for torsade de pointes and reverse use-dependence. Circulation, 93, 407-411. 